\title{
Annona muricata
}

National Cancer Institute

\section{Source}

National Cancer Institute. Annona muricata. NCI Thesaurus. Code C33900.

A common name for the tropical tree Annona muricata whose tissues contain annonaceous acetogenins, compounds with antineoplastic activity. Annonaceous acetogenins, derivatives of long-chain fatty acids, exhibit their anti-tumor properties by depleting cellular stores of adenosine 5 '-triphosphate (ATP), a primary source of energy in cells. These agents also inhibit ATP-driven drug resistance mechanisms. Possessing a broad range of therapeutic activities, graviola has been used in different cultures for its pesticidal, antifungal,, antispasmodic, anticonvulsant, vasodilator, smooth-muscle relaxant, and hypotensive properties. ( $\mathrm{NCl} 04)$ 